\title{
Direct Mass Spectroscopy Analysis and Comparison of Middle Eastern and Texas Crude Oils
}

\author{
Gamze Kaya ${ }^{*}$, Necati Kaya ${ }^{2}$, Mahmood Amani3 ${ }^{3}$ Abul H. M. J. Rahman³, \\ Alexandre A. Kolomenskii ${ }^{4}$, Hans A. Schuessler ${ }^{4}$ \\ ${ }^{1}$ Vocational School of Technical Sciences, Canakkale Onsekiz Mart University, Canakkale, Turkey \\ ${ }^{2}$ Faculty of Arts and Sciences, Giresun University, Giresun, Turkey \\ ${ }^{3}$ Petroleum Engineering Program, Texas A \& M University at Qatar, Doha, Qatar \\ ${ }^{4}$ Department of Physics, Texas A \& M University, College Station, TX, USA \\ Email: `gamzekaya@comu.edu.tr
}

How to cite this paper: Kaya, G., Kaya, N., Amani, M., Rahman, A.H.M.J., Kolomenskii, A.A. and Schuessler, H.A. (2017) Direct Mass Spectroscopy Analysis and Comparison of Middle Eastern and Texas Crude Oils. International Journal of Organic Chemistry, 7, 312-318.

https://doi.org/10.4236/ijoc.2017.74025

Received: September 28, 2017

Accepted: November 13, 2017

Published: November 16, 2017

Copyright ( 2017 by authors and Scientific Research Publishing Inc. This work is licensed under the Creative Commons Attribution International License (CC BY 4.0).

http://creativecommons.org/licenses/by/4.0/

\begin{abstract}
We analyzed two types of crude oil samples: Middle Eastern crude oil and Texas crude oil by using a residual gas analyzer (RGA) based on the linear quadrupole principle. This portable mass analyzer is capable of measuring hydrocarbons with masses of up to 300 atomic mass units $(\mathrm{amu})$ as well as low mass targets, such as methane and carbon dioxide at ppm level concentrations. The generated mass spectra revealed differences in the composition and signal intensity of hydrocarbons of Middle Eastern and Texas crude oil samples. Even if RGA 300 is manufactured to be served as a detailed gas analysis of vacuum systems, we have shown that it is sensitively capable of detection of hydrocarbons and it enables one to qualitative and quantitative analysis of the composition of the crude oils.
\end{abstract}

\section{Keywords}

Oil Composition, Mass Spectrum Analysis, Hydrocarbons Content

\section{Introduction}

Hydrocarbon-water phase behavior and solubility at high temperature and high pressure is very complex and varies widely. Moreover, extracting crude oil from HPHT (high pressure and high temperature) reservoir zones like the Texas Woodbine-Eagle Ford, the North Sea or the Middle Eastern fields, and preserving its original condition for analysis is costly and done only rarely [1]. The next 
best alternative is to have sample-testing equipment at the extraction point or at the well bore. Even when such samples are not analyzed at their down-hole condition, such remotely obtained and detailed data are a prerequisite in estimating the structure and capacity of wells, and for such analysis sensitive and selective equipment is required. At the same time this equipment must be rugged, since the wide range of hydrocarbons including heavy asphaltenes are in a mixed phase with water, crude oil and drilling mud.

The present work was performed in the laboratory since the samples came from the Middle East and from Texas. As is detailed below, the mass spectrometry profiles of the samples revealed their composition differences.

As an analytical method, mass spectrometry provides qualitative and quantitative analysis of the chemical compositions of a sample investigated, and for this purpose, several types of mass spectrometers have been produced and improved to serve for various applications. In recent years, the miniaturization of mass spectrometers, for example time-of-flight spectrometers [2], ion traps [3], sector mass filters [4], and quadrupoles [5] [6], has been given much consideration, so that such a device can be portable for field applications, while showing sufficient performance. Main advantages of these recent miniaturized mass analyzers are their lower cost and power consumption and the ability to operate at higher pressures and with smaller and less expensive vacuum systems [7].

Crude oil contains a variety of organic compounds; therefore, different techniques are required for detailed analysis of crude oil samples. While the determination of volatile and non-polar components has been achieved by gas chromatography/mass spectrometry (GC/MS), the identification of trace polar components in crude oil is performed using liquid chromatography/mass spectrometry (LC/MS) [8]. Mass spectrometric ionization techniques, namely, electron impact ionization (EI) [9], field ionization (FI) [10], and field desorption (FD) [11] are sufficient for analysis of volatile and semi volatile compounds in crude oil [8]. For the analysis of the compounds with higher boiling points, producing characteristic fragments, pyrolysis/mass spectrometry (Py/MS) or pyrolysis/gas chromatography/mass spectrometry (Py/GC/MS) needs to be considered [12]. Matrix-assisted laser desorption ionization/mass spectrometry (MALDI/MS) with the capability of detecting compounds in a wide range of mass-to-charge ratios is an effective method used for crude oil analysis in vacuum environment [13]. Electrospray ionization (ESI) [14] and atmospheric pressure photoionization (APPI) [15] are the other techniques used for crude oil analysis, but they require expensive instruments and complicated sample pretreatment.

We performed hydrocarbon analysis of crude oil with mass spectrometry, introducing the sample directly to the vacuum chamber without any prior sample preparation. A vacuum environment decreases the boiling temperature of the compounds drastically, and room temperature is enough for vaporization of most components from crude oil samples, therefore the signal is observed immediately. 


\section{Experimental Procedure}

To analyze Middle Eastern crude oil and Texas crude oil samples, which were obtained from the Middle Eastern fields and Texas Eagle Ford reservoir, respectively, we used the portable quadrupole mass analyzer (RGA300, Stanford Research Systems), which has RF frequencies in the several $\mathrm{MHz}$ range and quadrupole electrodes to separate different molecules. This portable mass analyzer has small dimensions, a mass range $1-300 \mathrm{amu}$ and the resolution better than 1 amu. The samples were injected into the vacuum chamber through a leak valve, and ions are produced by electron impact ionization. Thereby the electrons are produced by thermionic emission from a hot filament. Then by applying the radiofrequency field, the ions are separated according to their mass-to-charge ratios. The mass spectrometer is connected directly to a vacuum chamber, which contains vapor from the sample, as is shown in Figure 1. The spectrometer employs zero order (DC current for balancing the potential relative to the kinetic energy) and first order ( $\mathrm{AC}$ current with resonance frequency corresponding to mass over charge ratio) operation modes for detecting ions. These frequency domains multiplexed measurements give a high signal to noise ratio.

Besides the quadrupole probe, the RGA system includes an electronics control unit, and a real-time RGA Windows software, which is used for probe control, data acquisition and analysis. The probe unit consists of three parts: an ionizer, a quadrupole mass filter and an ion detector. The electronic control unit allows controlling the operation of the RGA and transmits the obtained data to the

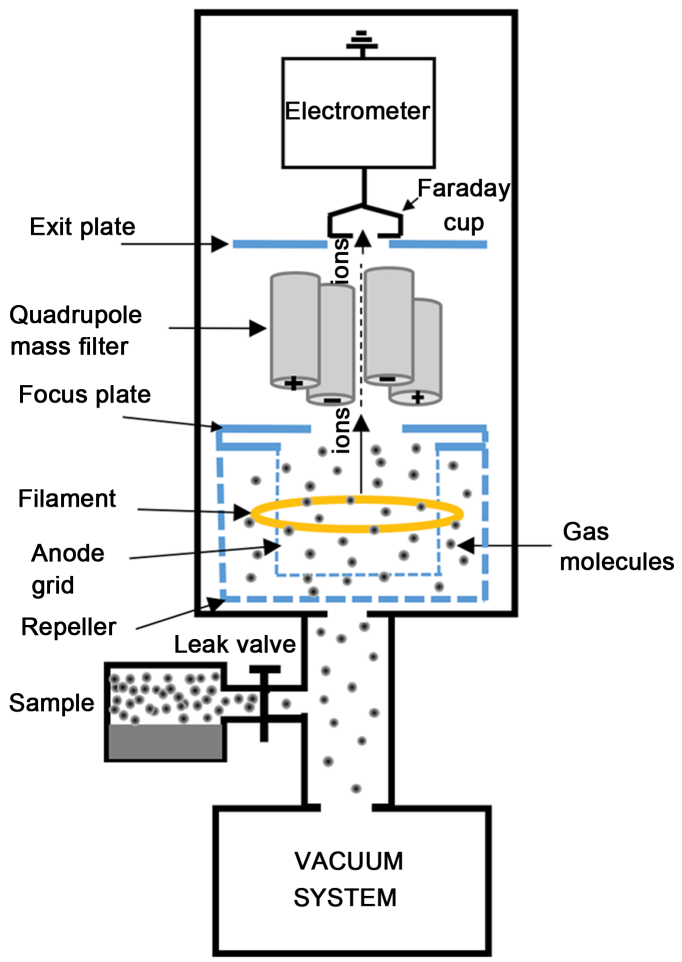

Figure 1. Schematic diagram of the mass spectrometry system used for analysis of crude oil samples. 
computer, where the data are displayed and analyzed. The electron emission is supplied by a dual thoriated-iridium $\left(\mathrm{ThO}_{2} / \mathrm{Ir}\right)$ filament, which lasts longer than single filaments. A Faraday cup detector allows partial pressure measurements in the range of $10^{-5}-10^{-11}$ mbar. An electron continuous-dynode electron multiplier (CDEM), with high sensitivity and fast scan rates is capable of detecting partial pressures down to $10^{-14}$ mbar. Finally, a high vacuum system turbomolecular pumping station TSU 071 provided by Pfeiffer Vacuum is connected with the residual gas analyzer. It assures low background pressure $\left(\sim 7.8 \times 10^{-7} \mathrm{mbar}\right)$ and enables maintenance of operational pressure for measurements at $\sim 5.2 \times 10^{-6}$ mbar.

\section{Results and Discussions}

The generated mass spectra and signal intensity of hydrocarbons in Middle Eastern and Texas crude oil samples are displayed together in Figures 2-4. The total measured range of mass-to-charge ratios was divided into three regions chosen at random for interpretation of data and comparison of the mass spectra: (a) 50 - $90 \mathrm{amu}$ (Figure 2); (b) $90-130 \mathrm{amu}$ (Figure 3); and (c) $130-171 \mathrm{amu}$ (Figure 4).

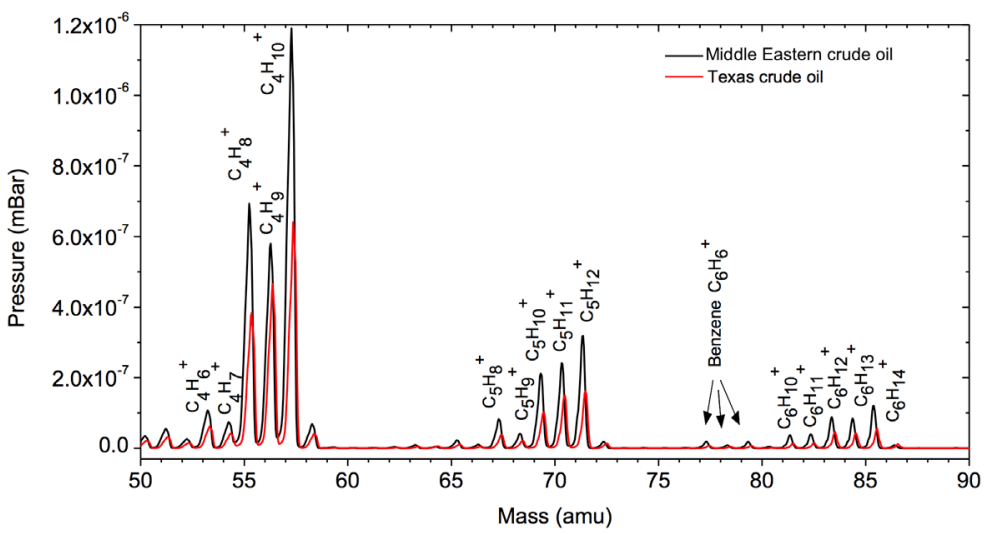

Figure 2. Crude oil hydrocarbon analysis of Middle Eastern crude oil and TX crude oil using RGA300 in the region 50 - 90 amu.

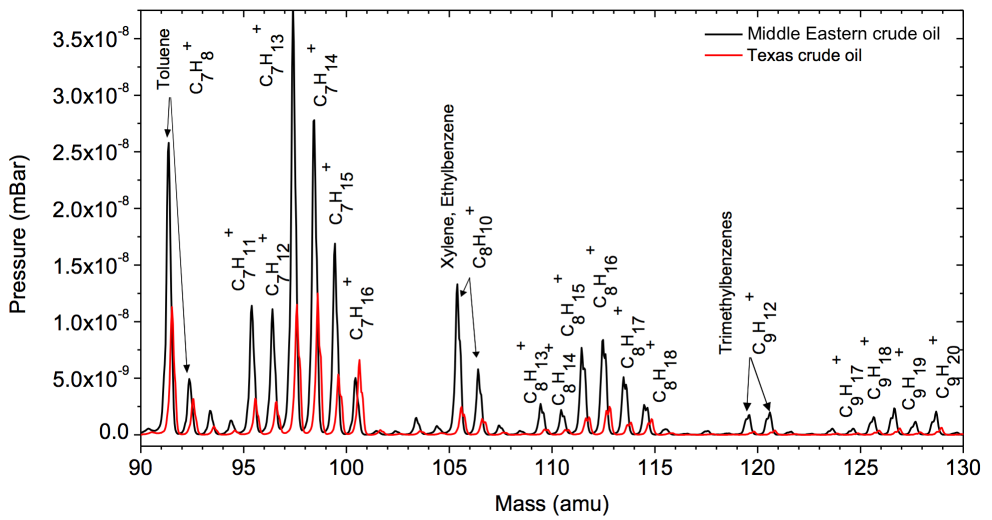

Figure 3. Crude oil hydrocarbon analysis of Middle Eastern crude oil and TX crude oil using RGA300 in the region 90 - $130 \mathrm{amu}$. 


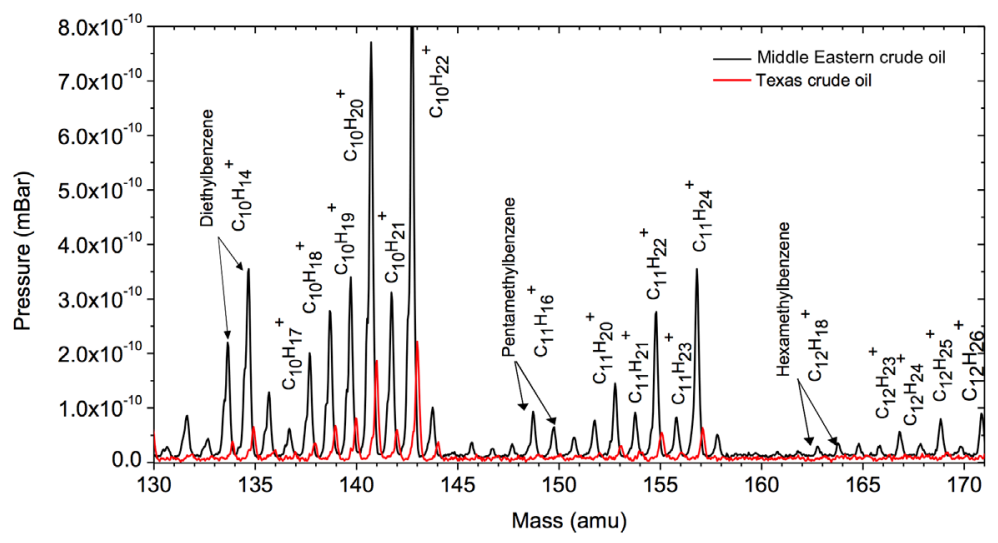

Figure 4. Crude oil hydrocarbon analysis of Middle Eastern crude oil and the TX crude oil using RGA300 in the region 130 - 171 amu.

Three major types of hydrocarbons in crude oil, i.e. paraffins, naphthenes, and aromatics are detected in both types of investigated samples. We observed linear and saturated hydrocarbons with mass-to-charge ratios $57,71,85,99,113,127$, $141,155,169 \mathrm{amu}$ and naphthenes (or cycloalkanes) with mass-to-charge ratios $55,69,83,97,111,125,139,153,167 \mathrm{amu}$. The aromatics seen with mass-to-charge ratios $77-78,91-92,105-106,119-120,133-134 \mathrm{amu}$ are characteristic of benzene derivatives. Toxic aromatic hydrocarbons, i.e. benzene, toluene, and xylene, with mass-to-charge ratios 77 - 78, 91 - 92, and 105 - $106 \mathrm{amu}$, respectively [16], are seen in both samples with significantly different signal intensities. The weak signals observed around mass-to-charge ratios $128 \mathrm{amu}$ and $141-142$ amu might be indicating the presence of naphtalene and methylnaphtalenes, respectively. While we have seen the peaks at 169 and $171 \mathrm{amu}$ in Middle Eastern crude oil, no such peaks were detected in Texas crude oil. We measured the whole mass range of our mass analyzer $1-300 \mathrm{amu}$, but above $171 \mathrm{amu}$ we did not detect any peaks in both samples. The abundance of hydrocarbons with higher mass-to-charge ratios in the region $91-171$ amu in Texas crude oil is significantly lower compared to Middle Eastern crude oil, as seen in Figure 3 and Figure 4. In Figure 5, the partial pressure ratio of different mass spectrum components of both crude oils by dividing pressure ratios of Middle Eastern crude oil to Texas crude oil is plotted, and it shows that the abundance of hydrocarbons of Middle Eastern crude oil compared to Texas crude oil is higher by a factor that ranges for different components from 4 to 21 .

\section{Conclusion}

Analysis of two different types of crude oil samples, Middle Eastern crude oil from the Middle Eastern fields and Texas crude oil obtained from Texas Eagle Ford reservoir zones, by the portable quadrupole mass analyzer under vacuum condition without any sample pretreatment is performed. The mass spectra of these two types of oil samples show differences. The Middle Eastern crude oil samples show significant prevalence of hydrocarbons in the range of $90-160 \mathrm{amu}$. 


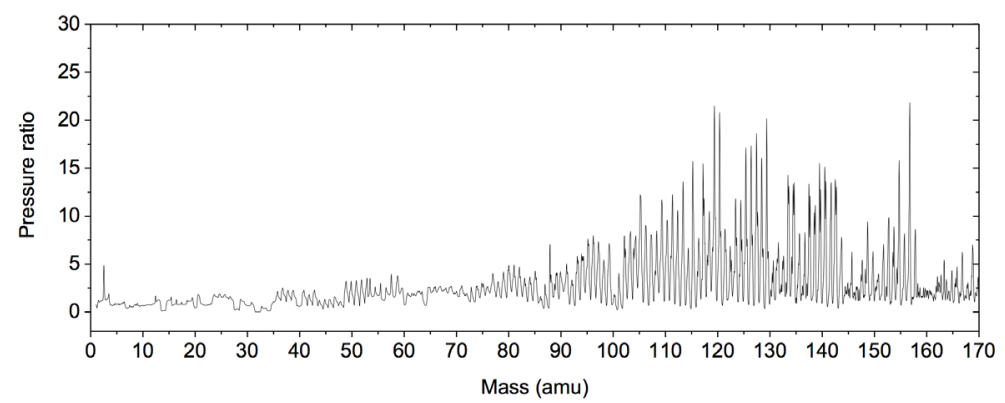

Figure 5. Partial pressure ratio of crude oil mass spectra of Middle Eastern crude oil and Texas crude oil.

Moreover, two crude oil samples reveal some differences in composition. We observed C12 paraffin, naphthene, and aromatic hydrocarbons only in Middle Eastern crude oil. Even though our measurements were done at the laboratory conditions, due to portability and rather small size of the equipment, the same approach is suitable for in-field applications if needed.

\section{Acknowledgements}

This work was supported by the Robert A. Welch Foundation (grant No. A1546).

\section{References}

[1] Shadravan, A. and Amani, M. (2012) HPHT 101-What Petroleum Engineers and Geoscientists Should Know about High Pressure High Temperature Wells Environment. Energy Science and Technology, 4, 36-60.

[2] Cotter, R.J., Fancher, C. and Cornish, T.J. (1999) Miniaturized Time-of-Flight Mass Spectrometer for Peptide and Oligonucleotide Analysis. Journal of Mass Spectrometry, 34, 1368-1372.

https://doi.org/10.1002/(SICI)1096-9888(199912)34:12<1368::AID-JMS905>3.0.CO;2-S

[3] Ouyang, Z., Wu, G., Song, Y., Li, H., Plass, W.R. and Cooks, R.G. (2004) Rectilinear Ion Trap: Concepts, Calculations, and Analytical Performance of a New Mass Analyzer. Analytical Chemistry, 76, 4595-4605. https://doi.org/10.1021/ac049420n

[4] Sinha, M.P. and Tomassian, A.D. (1991) Development of a Miniaturized, Light-Weight Magnetic Sector for a Field-Portable Mass Spectrograph. Review of Scientific Instruments, 62, 2618-2620. https://doi.org/10.1063/1.1142240

[5] Freidhoff, C.B., et al. (1999) Chemical Sensing Using Non-Optical Microelectromechanical Systems. Journal of Vacuum Science \& Technology A, 17, 2300-2307. https://doi.org/10.1116/1.581764

[6] Badman, E.R. and Cooks, R.G. (2000) Miniature Mass Analyzers. Journal of Mass Spectrometry, 35, 659-671.

https://doi.org/10.1002/1096-9888(200006)35:6<659::AID-JMS5>3.0.CO;2-V

[7] Brkić, B., France, N., Clare, A.T., Sutcliffe, C.J., Chalker, P.R. and Taylor, S. (2011) Development of Quadrupole Mass Spectrometers Using Rapid Prototyping Technology. Journal of the American Society for Mass Spectrometry, 20, 1359-1365. https://doi.org/10.1016/j.jasms.2009.03.025

[8] Cheng, C.N., Lai, J.H., Huang, M.Z., Oung, J.N. and Shiea, J. (2012) Analysis of Po- 
lar Components in Crude Oil by Ambient Mass Spectrometry. In: El-Sayed Abdul-Raouf, M., Ed., Crude Oil Emulsions, Composition Stability and Characterization, InTech, 107-120. https://doi.org/10.5772/36261

[9] Flego, C. and Zannoni, C. (2010) Direct Insertion Probe-Mass Spectrometry: A Useful Tool for Characterization of Asphaltenes. Energy \& Fuels, 24, 6041-6053. https://doi.org/10.1021/ef100984y

[10] Hsu, C.S. and Green, M. (2001) Fragment-Free Accurate Mass Measurement of Complex Mixture Components by Gas Chromatography/Field Ionization-Orthogonal Acceleration Time-of-Flight Mass Spectrometry: An Unprecedented Capability for Mixture Analysis. Rapid Communications in Mass Spectrometry, 15, 236-239.

https://doi.org/10.1002/1097-0231(20010215)15:3<236::AID-RCM197>3.0.CO;2-B

[11] Stanford, L.A., Kim, S., Klein, G.C., Smith, D.F., Rodgers, R.P. and Marshall, A.G. (2007) Identification of Water-Soluble Heavy Crude Oil Organic-Acids, Bases, and Neutrals by Electrospray Ionization and Field Desorption Ionization Fourier Transform Ion Cyclotron Resonance Mass Spectrometry. Environmental Science \& Technology, 41, 2696-2702. https://doi.org/10.1021/es0624063

[12] Snyder, A.P., McClennen, W.H., Dworzanski, J.P. and Meuzelaar, H.L.C. (1990) Characterization of Underivatized Lipid Biomarkers from Microorganisms with Pyrolysis Short-Column Gas Chromatography/Ion Trap Mass Spectrometry. Analytical Chemistry, 62, 2565-2573. https://doi.org/10.1021/ac00222a010

[13] Robins, C. and Limbach, P.A. (2003) The Use of Nonpolar Matrices for Matrix-Assisted Laser Desorption/Ionization Mass Spectrometric Analysis of High Boiling Crude Oil Fractions. Rapid Communications in Mass Spectrometry, 17, 2839-2845. https://doi.org/10.1002/rcm.1275

[14] Zhan, D. and Fenn, J.B. (2000) Electrospray Mass Spectrometry of Fossil Fuels. International Journal of Mass Spectrometry, 194, 197-208. https://doi.org/10.1016/S1387-3806(99)00186-4

[15] Purcell, J.M., Hendrickson, C.L., Rodgers, R.P. and Marshall, A.G. (2006) Atmospheric Pressure Photoionization Fourier Transform Ion Cyclotron Resonance Mass Spectrometry for Complex Mixture Analysis. Analytical Chemistry, 78, 5906-5912. https://doi.org/10.1021/ac060754h

[16] Brkić, B., France, N. and Taylor, S. (2011) Oil-in-Water Monitoring Using Membrane Inlet Mass Spectrometry. Analytical Chemistry, 83, 6230-6236.

https://doi.org/10.1021/ac2008042 